\title{
Participatory Air Monitoring in the Midst of Uncertainty: Residents' Experiences with the Speck Sensor
}

\author{
JACOB MATZ $^{1}$ \\ NORTHEASTERN UNIVERSITY \\ SARA WYLIE \\ NORTHEASTERN UNIVERSITY \\ JILL KRIESKY

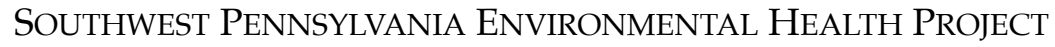

\begin{abstract}
How do participants engage in at-home air monitoring in the midst of uncertain exposures to airborne emissions associated with unconventional natural gas development (UNGD) activities? We investigate residents' experiences with the "Speck" particulate matter sensor with an emerging environmental health resource center called the Southwest Pennsylvania Environmental Health Project (EHP). In response to the gaps in knowledge about the health impacts of UNGD and the growth citizen science tools, participatory environmental monitoring (PEM) projects have taken off in shale gas communities. Using interview and survey data from residents, advocates, and activists we show that residents use the Speck as: 1) "environmental health thermometers" to make real time decisions based on readings; 2) real-time tools of exposure-validation to immediately validate or invalidate suspicions of exposure; 3) "epistemic objects" or tools manipulated in exploratory ways to understand their efficacy in monitoring UNGD; and 4) passively by those who chose to rarely interact with the monitors and rather waited for overall analysis of results. While PEM's have been critiqued for potentially passing the burden of monitoring onto communities, our research shows PEM, when connected with
\end{abstract}

\footnotetext{
1 Jacob Matz, Email: matz.j@husky.neu.edu

Copyright ( 2017 (Jacob Matz, Sara Wylie, and Jill Kriesky). Licensed under the Creative Commons Attribution Noncommercial No Derivatives (by-nc-nd). Available at estsjournal.org.
} 
research and public health organizations like EHP, can both empower individuals by increasing their perceived and actual agency and build collective knowledge by producing novel scientific findings. The modes of participation identified here each imply individual and community-level outcomes. When connected with an organization like EHP, Speck monitoring enabled participating individual the latitude to develop their own research and make immediate use of the data, while also creating data useful for aggregated scientific analyses that provoke new questions about the health risks associated with UNGD.

\section{Keywords}

fracking; citizen science; air monitoring; Marcellus shale

\section{Introduction}

Samantha ${ }^{2}$ was working in her yard in Pennsylvania, when some shale gas wells down the road began to "flare," or burn off gas by lighting it on fire. She became short of breath and struggled to traverse the steep hillside. As emissions from the flare settled in the valley, she went inside and looked at her Speck Sensor. Distributed by a local nonprofit environmental-health resource center called the Southwest Pennsylvania Environmental Health Project (EHP), the Speck is a sensor that measures and monitors air pollutants associated with unconventional natural gas development (UNDG) in real time. Inside her home, Samantha saw that the sensor was "off the charts" and "completely red" - a designation of unhealthy levels of particulate matter (PM).

Samantha had long experienced what she understood to be the unhealthy effects of living near UNGD, and for the last few years, taking part in environmental studies and monitoring, she worked to validate her suspicions. Interviewing her for this study, we sat at her dining table, which had become the desk of a researcher--a place for her to work to understand her exposures in an effort to resist impacts. Piled upon the dining table were stacks of university, industry, and independent monitoring results; records of conversations with industry representatives; letters to and from regulators and lawmakers; legal documents; correspondences from researchers; and of course, a Speck-plugged in and humming next to the other tools that Samantha had compiled to validate her bodily senses and place them in the context of exposures to UNGD.

\footnotetext{
${ }^{2}$ All names have been changed to protect anonymity.
} 
The scene seemed characteristic of communities with limited resources scrambling to make sense of the fast-paced and well-funded UNGD boom, where some residents are taking environmental research into their own hands to document exposures and sicknesses that might otherwise go unrecorded, and thus unconnected to the industry. Samantha used her water tests results showing contamination of her well to convince her neighbors to test their water, and the town to pipe city water to her home. Her Speck data, combined with that of other residents, contributed to EHP's analysis and understanding of how $\mathrm{PM}_{2.5}$ from UNGD is impacting their health.

\section{UNGD and the Speck}

Samantha's case is one of many in southwest Pennsylvania, a hotspot for both UNGD and participatory environmental monitoring (PEM) projects (Jalbert et al. 2014; Kinchy et al. 2014). Southwest Pennsylvania sits atop the Marcellus shale-a seam of oil and gas bearing sedimentary rock that extends across West Virginia, Ohio, Pennsylvania, and New York. With the development of horizontal drilling and high volume hydraulic fracturing, or "fracking," the energy industry can drill across shale formations and inject millions of gallons of chemical-laden water at high pressure to create fractures in the shale formation. These fractures release the hydrocarbons embedded in the shale (Lampe and Stolz 2015; McGraw 2012). UNGD is often referred to as "fracking," but fracking is just one step in a larger process of industrial shale gas development. UNGD includes construction of the pad, drilling the well, stimulating the well by fracking, extraction, production, and transportation to remove fossil fuels and waste.

This new form of energy production poses risks to environmental health from air and water pollution and threats to social and psychological well-being (Perry 2012; Subra 2012; Colborn et al. 2011; Brown 2014; Rabinowitz et al. 2014; Steinzor et al. 2013 Schmidt 2011). Air pollutants include particulate matter (PM); methane and greenhouse gases; polycyclic aromatic hydrocarbons (PAHs); and volatile organic compounds (VOCs) (Bolden et al. 2015; Werner et al. 2015; Brown 2014; Macey et al. 2014). Supporters of UNGD often contest claims of negative impacts. For instance, Energy in Depth, a PR organization founded by the Independent Petroleum Association of America, regularly dismisses claims of researchers and activists as radical, disingenuous, and/or obstructionist (Matz and Renfrew 2014). However, amid contestations, residents and researchers are working together to bring exposures into relief through participatory environmental health monitoring (PEM) projects (Hays and Shonkoff 
2016; Kriesky 2015; Jalbert et al. 2014; Kinchy et al. 2014; Wylie and Albright 2013; Macey et al. 2014; Steinzor et al. 2013).

EHP's Speck initiative is illustrative of PEM in UNGD regions. It brings together residents impacted by exposures with an interdisciplinary network of researchers and advocates to understand how exposures are related to health, and to bring contested environmental exposures into public and regulatory view (Wylie et al. 2014). Our analysis offers the first descriptive account of engagement with the Speck and a case study of involvement with a lowcost civic science monitor.

The Speck is a small black box with a $\sim 3$ inch LCD screen that shows real-time $\mathrm{PM}_{2.5}$ measurements in the context of the EPA AQI. The device was developed in 2011 by the Community Robotics, Education and Technology Empowerment Lab (the CREATE Lab), a development team at Carnegie Mellon University, also funded in part by the Heinz Endowments $^{3}$ (Heinz 2009). In efforts to test and promote the use of the Speck, the CREATE Lab donated thousands of units to CBOs across the region (Page-Jacobs 2015; Spice 2015). A partnership between the CREATE Lab and EHP allowed EHP to provide over 300 Specks to households in the Marcellus region to monitor PM as a surrogate of exposure to air pollution from UNGD. Together, EHP and the CREATE Lab have circulated three versions of the Speck throughout the region: two prototypes (Speck-A and B) and the commercially-available Speck-C (Rouvalis 2015).

Through the analysis of interview and surveys with residents, advocates, sensor developers, and activists, we identify four modes of engagement with the Speck: 1) as "environmental health thermometers" to evaluate air quality and make immediate environmental health decisions; 2 ) as real-time tools of exposure-validation to confirm (or deny) suspicions of exposure for themselves and others; 3 ) as "epistemic objects" or tools manipulated in exploratory ways to understand their efficacy in monitoring UNGD (Rheinberger 1997; Knorr Cetina 2001); and 4) Specks are used passively by those who rarely interact with the monitors. While categories aren't mutually exclusive, they provide a framework for understanding how communities exposed to toxic threats participate in PEM to build their knowledge of exposure, to validate their exposure experiences, to make individual and social decisions, and to provoke questions about the risks of UNGD (Allen 2003).

\footnotetext{
${ }^{3}$ The CREATE Lab is an academic robotics team that collaborates with CBOs in order "to promote evidence based decision making, public discourse and action" through robotics development, low-cost sensing technologies, visualization tools, and data-sharing platforms (CREATE 2014).
} 


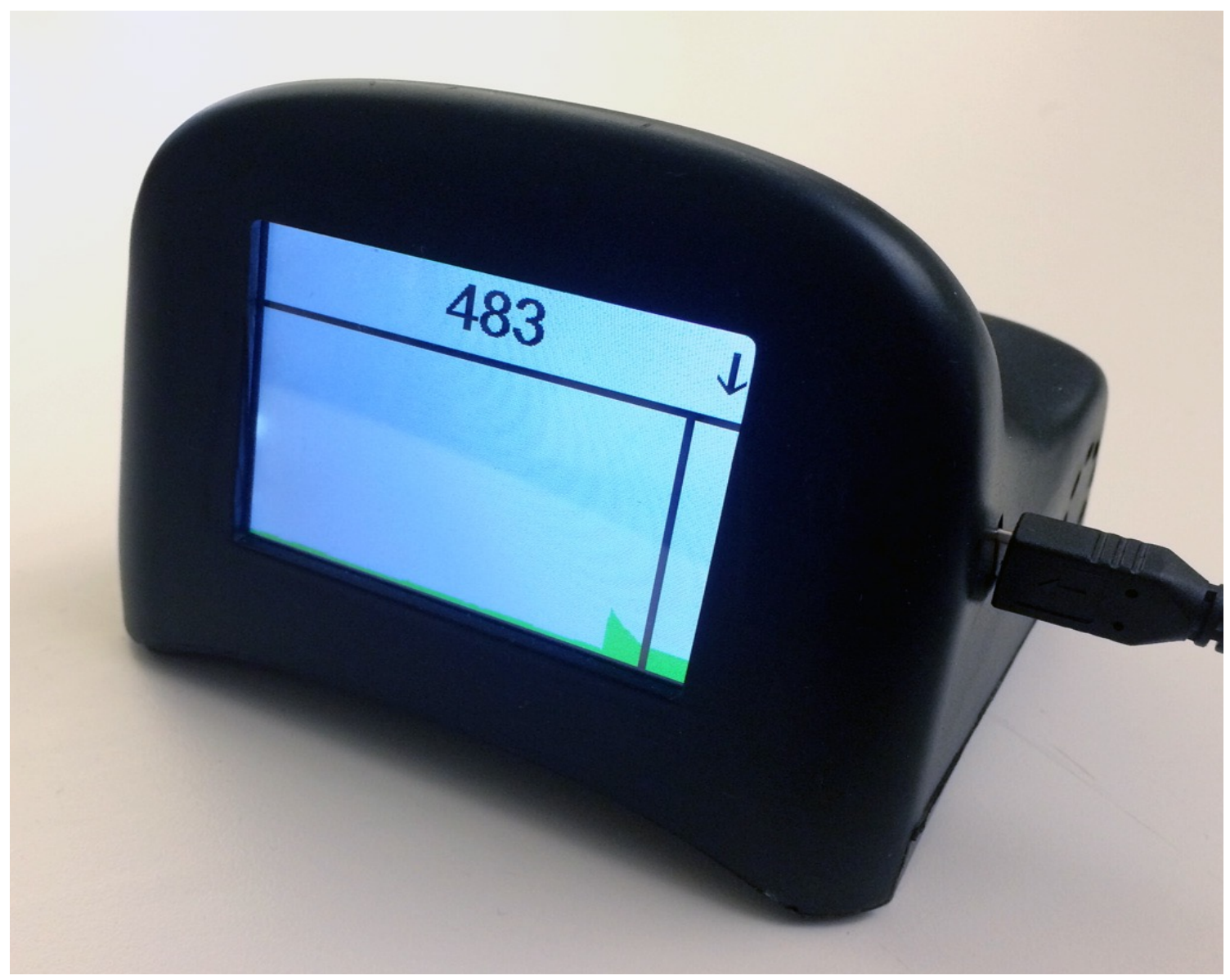

Figure 1: Speck-A (Bartley 2014).

Further, we argue that Speck use is not limited to a neoliberal framework of individual accountability. Designed to be sold on the market, the Speck could be viewed as a neoliberal response to air pollution and characteristic of attempts to manage structural health problems through individual consumption (Szasz 2007; Steinberg 2010). Yet, we counter the anticipated critique of "green liberalism" in the context of EHP's PEM and suggest an alternative formulation.

Three potential concerns about PEM are that 1) citizen scientists are unable to create usable quality-controlled data; 2) that PEMs unfairly place the burden of monitoring on communities (Kinchy et al. 2012); 3) and that individual level monitors like the Speck create individual solutions to structural problems like UNGD (Steinberg 2010). This paper explores 
these concerns via interviews with Speck Users and EHP. It finds that the Speck monitoring project conducted by EHP supports a range of engagements on the part of users, from passive engagement to users actively developing their own research with the device. This latitude is unusual for citizen science, which historically dictates from the top-down how data should be gathered (Follet and Strezvov 2015). Traditionally, such data are not immediately useful to participants but rather sent onto researchers who aggregate and interpret the data (Wylie et al. 2014). The lag in this research model between research and action creates problems for the frontlines of environmental health issues, as residents need immediately actionable data to make decisions. However, when combined with a research organization like EHP, we argue that Speck monitoring provides novel solutions to these issues, by 1) providing users with the freedom to engage with monitoring as they see fit; 2) providing them with data that are immediately useful; and 3) creating data that can be used for scientific research.

"Citizen science," often invoked in discussions of PEM, is a broad term is used to describe a range of activities, from crowd-sourced bird-counting to support academic research, to community-based participatory research (CBPR) in which a CBO might partner with academics to monitor exposures in the pursuit of actionable-data for environmental justice (Minkler et al. 2010; Corburn 2005; Minkler and Wallerstein 2003; Israel et al. 1998). EHP's Speck project is not typically "citizen science" or CBPR. In most cases, EHP monitoring is conducted with individual residents who may or may not share their results, rather than a specific advocacy CBO. It is not a typical air quality study because the goal is not to test a hypothesis for scientific publication but rather to provide timely environmental health information to residents for individual intervention. Typically, each resident is an " $\mathrm{n}$ of 1 " in their own personal research project with the Speck. However, the flexibility in EHP study design allows for a variety of modes of engagement and a range of interventions, both social and individual. For instance, EHP has used the Speck project to build the argument in academic papers that EPA measurements of air pollution base air quality only on averages rather than on episodic exposures and significant variability throughout the day, and so fail to identify unsafe levels of $\mathrm{PM}_{2.5}$ to which residents are regularly exposed (Brown et al. 2015; Brown et al. 2014, 12). Additionally, residents report sharing Speck results with local government officials, zoning boards, school board officials, CBOs, neighbors, health care providers, industry personnel, and the media-evidence of Speck use to geared to contest the industry and to activate social and political discourses on health and UNGD. EHP distributes Specks to a range of activist and civic organizations where members have shared results in efforts to contest shale gas development. The flexibility of EHP's design, its focus on empowering the individual to monitor as they see fit, 
and its success in building academic arguments, suggest that it is possible to design structures for citizen science that marry the individual's need for immediately useable results and autonomy with the academic need for synoptic and synthetic data analysis through the operations of organizations like EHP. Thus, EHP offers an effective model for community research or "civic science" that both responds to needs on the ground and provides new scientific knowledge (Fortun and Fortun 2005; Wylie et al. 2014).

\section{Methods}

In 2014, authors worked in collaboration with EHP to evaluate the Speck project through interviews with users. EHP spent the prior 10 months distributing monitors to residents and advocacy/activist organizations; analyzing Speck results; receiving and fulfilling requests for monitors from the community; and communicating results to residents. EHP enrolled social scientists to speak with residents and organizations about the Speck project; their experiences with the device; and their experiences with EHP. This CBO/academic collaboration aimed to assist EHP in reflecting on the delivery of the Speck and its results, and to maintain lines of communication with the residents who had used the Speck. The Specks were new, the Speck project was new, and follow up with users was a vital part of the community-monitoring project.

The authors conducted 18 semi-structured interviews with 24 individual users at homes, workplaces, and over the phone. This sample includes residents who had received a Speck from EHP; members of advocacy and activist organizations networked with EHP; members of EHP engaged in the distribution and analysis of Speck results; and the developers of the Speck at the CREATE Lab. Sampling was largely purposive and snowballing. Furthermore, the authors developed and mailed a questionnaire to 56 Speck users. 18 questionnaires of the 56 questionnaires were received (a response rate of 32\%). This response rate may be characteristic of the temporal and/or psychological burden of participation in research for communities already dealing with health impacts who are subsequently asked to take part in research or share personal health stories (Harrison 2011; Rich et al. 1995; Edelstein 1988).

\section{Data Gaps, Exposures, and the Development of EHP}

The "exposure experience" is the lived and embodied experience of being chronically subjected to pollution (Adams et. al 2011; Altman et al. 2008). While exposures are experienced physically, they are also inflected by socially produced uncertainties-a lack of clear information from 
government, conflicting information from the media, a lack of data, contestation by industry, and little context for understanding risk (Edelstein 1988; Beck 1992; Auyero and Swistun 2007). Pollutants themselves are often physically ambiguous or invisible, compounding this uncertainty (Edelstein 1988).

UNGD expanded rapidly in southwest PA with little active protection of human or environmental health. The first well was drilled in 2004, and by 2015 the number has climbed to approximately 2,500 wells (Amico, et al. 2014; McGraw 2012). Residents interviewed here reported a multitude of health impacts that they associated with the boom: dermal, respiratory, and gastro-intestinal, psychological, and others mirroring preliminary community health studies (Steinzor et al. 2013; Bamberger and Oswald 2012; Subra 2012). They associated these with wells, compressors, pipelines, processing, truck-traffic, noise, dust, and light. There are few frameworks to understand outcomes or health risks, and while scientific evidence of negative outcomes is mounting, a definitive epidemiological study has not been conducted (Hays and Shonkoff 2016; Werner et al. 2015; Shonkoff et al. 2014). Further, UNGD operations are afforded key federal environmental exemptions (Kosnik 2007).

In interviews, residents often expressed a sense of frustration over the lack of governmental oversight, clear information, and distrust of regulatory agencies; such anxieties are documented in UNGD regions elsewhere (Briggle 2015; Gullion 2015). In fact, official state air monitoring in UNGD regions is sparse, and in many ways residents are turning to the Speck to offset this oversight. Monitors are often centered in urban areas, and can miss rural pollution (Carlton et al. 2014; Colborn et al. 2014). ${ }^{4}$ Map 1 shows a lack of EPA PM 2.5 air monitoring coverage of UNGD areas in Pennsylvania. Blue dots represent monitoring stations, and the shades of green the relative density of wells. There is little overlap between densely drilled areas and EPA $\mathrm{PM}_{2.5}$ air monitors. EHP's Speck monitoring project emerged in part to fill this significant hole in $\mathrm{PM}_{2.5}$ monitoring.

In 2012, EHP opened as a resource center for residents concerned about exposures to UNGD pollution. They developed an environmental health "analysis and intervention" model with the goal of empowering people to protect their health even while the threats and the science around UNGD are uncertain. EHP resulted from tours hosted by The Center for Healthy Environments and Communities, a community-based research center (CHEC) housed at the

\footnotetext{
${ }^{4}$ Pennsylvania is not alone in this problem. Macey, et al. (2014) point out that in Texas and Colorado, state air-monitoring activities do not tend to coincide with rural UNGD. In the Texas Eagle Ford shale, 7,000 UNGD wells are monitored by just five air-monitoring stations. In Garfield County, Colorado, public health officials monitor around 3,000 square miles of mountainous, UNGD terrain with just five air monitors (Macey et al. 2014).
} 
University of Pittsburgh's School of Public Health. CHEC's tours of impacted regions brought together health professionals, academics, and advocates to speak with community members. ${ }^{5}$ EHP is the result of conversations between health professionals, foundation funders, academics, and residents brought together by tours of impacted regions. These diverse perspectives produced EHP's unique model of both offering practical medical advice through nurse practitioners to impacted families and gathering health and emissions data to explore the links between UNGD activity and health.

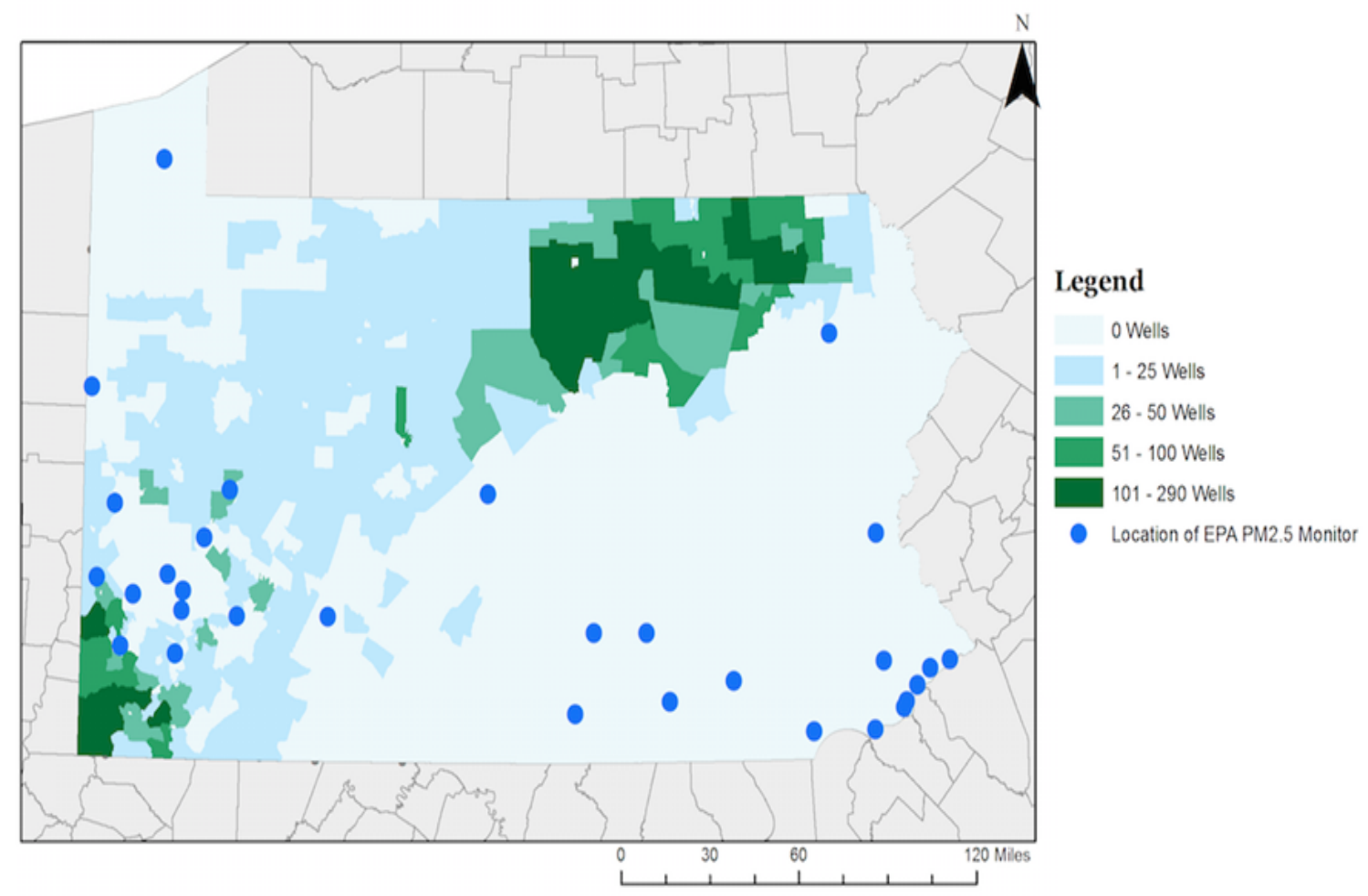

Map 1: EPA PM2.5 Monitoring Stations in PA.

EHP operates from the public health model of the Center for Disease Control. This approach finds the potential pathway(s) of exposure, establishes mitigation methods, and disseminates public information. EHP works to 1) identify and document health impacts associated with UNGD; 2) determine the localized sources of these impacts; and 3) provide

\footnotetext{
${ }^{5}$ CHEC developed these tours based on their experiences in environmental sampling and interviewing impacted residents since the late 2000's.
} 
recommendations for interventions. This includes collecting and analyzing health data, developing environmental monitoring protocols to determine the cause of symptoms; developing health interventions; and disseminating information to individuals, CBOs, and government agencies.

EHP offers a range of environmental health resources, free of charge, designed to evaluate a range of symptoms related to exposure, and propose intervention. In addition to environmental monitoring, this includes: physical and psycho-social impact assessments, consultations, and referrals from nurse practitioners; and educational consultations for medical professionals, CBOs, and government agencies. Screenings and monitoring provide immediate information to residents, while data gathering and analysis allow EHP to make recommendations to scientific, medical, and policy communities. The combination offers a comprehensive approach to healthcare and intervention that, to our knowledge, is not currently in practice elsewhere.

EHP's fusion of data gathering and analysis, and intervention and residency in impacted communities, unintentionally returns to an early heritage in environmental health work from the progressive era in the US (Sellers 1997; Murphy 2006). In the progressive era organizations such as the Hull House promoted the three " $\mathrm{R}$ 's" approach to environmental health: Residency, Research, and Reform (Wade 1967; Addams 1892). This movement saw these three activities as mutually constitutive. Through residency, researchers built trust and an experiential understanding of peoples' everyday experience of health threats. Living in the community made health problems evident and close ties to the community made research with residents feasible. Using this model, Alice Hamilton first systematically recorded the health problems developed by workers exposed to lead (Sellers 1997). These community-based connections similarly became the emotional foundation for the final R: reform. Hamilton and the Hull House were the first to push for regulating lead exposures in the workplace. While EHP does not engage in direct advocacy, they provide advocacy and activist organizations with information that is used politically. Even so, EHP can be viewed as a contemporary form of this progressive era model of research with a post-modern twist--the use of low cost electronics that themselves are not without uncertainties.

\section{Particulate Matter and UNGD}

When EHP first opened, residents overwhelmingly reported concerns about the visible and invisible air pollution associated with UNGD and its impact on their health. This prompted EHP 
to seek low-cost ways to model exposures to air emissions, leading to a focus on PM and the use of the Speck. PM measurement with the Speck is low-cost; PM can be continuously monitored across UNGD processes; and PM is associated with the presence of volatile organic compounds (VOCs) and polycyclic aromatic hydrocarbons (PAHs) (Werner et al. 2015; Brown et al. 2014; Adgate et al. 2014), which have a range of mild to carcinogenic health impacts.

PM is a mixture of microscopic solid and liquid particles, including organic hydrocarbons, metals, nitrates, sulfates, and dust (Nel 2005; EPA 2003). It is produced by sources like vehicle exhaust and industrial activities (Nel 2005). PM $\leq 2.5$ micrometers in diameter is considered fine particles $\left(\mathrm{PM}_{2.5}\right) .{ }^{6} \mathrm{EPA}$ regulates $\mathrm{PM}_{2.5}$ as one of six criteria air pollutants deemed harmful to health and the environment under the Clean Air Act (Graham 2011). Annual and 24hour averages of $\mathrm{PM}_{2.5}$ are measured using the EPA Air Quality Index (AQI) as defined by National Ambient Air Quality Standards (NAAQS) (EPA 2003).

$\mathrm{PM}_{2.5}$ is associated with acute and long-term health impacts to the cardiovascular and respiratory systems and is linked to an increase in hospital visits, lung cancer, asthma, chronic bronchitis, chronic obstructive pulmonary disease (COPD), dysrhythmia, low birth weight, and pre-term birth (DeFranco et al. 2016; Stieb et al. 2016; Marino et al. 2015; Raaschou-Nielsen et al. 2013; Dominici et al. 2006; Nel 2005; EPA 2003). Exposure is especially harmful to children, the elderly, and individuals with existing respiratory or cardiovascular conditions (Brown et al. 2014; EPA 2014; WHO 2013). PM $_{2.5}$ and ultrafine PM are small enough to potentially travel deep into the lungs, enter the alveoli, and permanently alter the small airways (EPA 2003; Churg et al. 2003). Ultrafine PM can continue into the bloodstream with uncertain long-term impacts on health (Nemmar et al. 2002). Not only is the science around PM exposure uncertain and the degree of PM exposure during UNGD uncertain; the low cost tools for detecting PM are also evolving. The Speck monitor is one of the first low cost air quality monitoring devices designed to be used by the general public rather than experts (Williams et al. 2014). EHP's project was part of the device's pilot testing.

$C M U, E H P$, and the Speck Project

In 2012, EHP began distributing Specks where they are placed inside and outside of homes to collect and display $\mathrm{PM}_{2.5}$ measurements. After three to four weeks, EHP collected the Specks to analyze each home's air quality. This analysis was returned to each individual resident in a report of hourly $\mathrm{PM}_{2.5}$ results; possible sources of exposure; the relationship between air quality, nearby UNGD and health; and intervention strategies to reduce exposure. Reports

${ }^{6} \mathrm{PM}_{2.5}$ and ultrafine $\mathrm{PM}(<0.1 \mu \mathrm{m}$ in diameter) are associated with the combustion of fossil fuels (Nel 2005, 804). 
include sections describing $\mathrm{PM}_{2.5}$, the role that weather and geography play in daily PM levels, ${ }^{7}$ and recommendations of actions to take in response.

Residents interviewed here used Speck versions A and B. Speck-A, was limited to displaying counts $/ \mathrm{m}^{3}$ of $\mathrm{PM}_{2.0}$, a measure not regulated by EPA AQI. Speck-B was updated through machine learning to correspond with EPA AQI and display $\mathrm{PM}_{2.5}$ concentrations. ${ }^{8}$ However, Speck data are not federally recognized measurements of particulate matter and cannot legally assess poor air quality. The EPA published an evaluation of a Speck-A device in 2014. This evaluation showed a lack of correlation with an EPA federal equivalent method (FEM) PM monitor (Williams et al. 2014). However, the evaluation faced multiple challenges: (1) only one Speck-A device was tested; (2) the device suffered a hardware malfunction, causing seemingly random peaks in PM; and (3) Speck data timestamps were misread, impacting the comparison of EPA and Speck PM data. ${ }^{9}$

EHP's work with the Speck was therefore conducted amidst a threefold uncertainty: uncertainty in the monitoring device, uncertainty in how the device was used, and uncertainty in routes of exposure. EHP became a social and technical medium for modulating these uncertainties and producing new knowledge of this shifting terrain. Faced with an absence of any data about PM production and exposures during UNGD the Speck provided a promising baseline even if the data were not regulation quality. Additionally, it could be used continuously and affordably across locations.

\footnotetext{
${ }^{7}$ EHP designed an air-screening model to assist air exposure assessment for both particulates and gases. The elements of the model are based on publicly available emissions estimates from UNGD sources, a simple box model dispersion assumption of the pollutant plume, and the Pasquill stability classifications categorized by wind speed and degree of cloud cover for daytime and nighttime conditions. Since the air model does not rely on monitored pollutant values, it can be used to inform the interpretation of the Speck results, both by the residents and the EHP staff

${ }^{8}$ Speck C is commercially available and owned by a CREATE Lab-spinoff company called Airviz. Data can be uploaded to a PC and/or an online PM data repository managed by the CREATE Lab (Airviz 2015).

${ }^{9}$ The Speck is not a FEM, and it remains unclear how and if Speck data will be used in a legal setting.
} 
To manage uncertainties of the Specks themselves, EHP added their own quality control protocols on top of the CREATE Lab's own calibration processes. ${ }^{10}$ EHP tested the Speck against the current hourly AQI estimates to ensure validity. And double-checked them for consistency by comparing their readings against one another, and against a Speck in the EHP office (EHP 2015). Additionally, when hardware failures caused misreadings in Speck-A's, EHP identified and replaced those units. Acting as a co-ordinating hub EHP helped assure the validity of Speck devices. $^{11}$

\section{The Environmental Health Thermometer}

The Speck allowed users to visualize otherwise obscured air quality information. Many residents watched Specks to make immediate decisions. Just as one would use a thermometer to visualize temperature and decide how to dress, residents used the Speck to decide whether or not to keep their windows open, to go outside, or to remain on their property. Just like a thermometer, the Speck reaffirmed the senses and suggested a course of action.

UNGD has significantly altered David and Greta's lives. The couple lived in rural PA for decades. They hadn't signed any leases with the energy industry-they didn't own rights to the minerals beneath their land, and they didn't want UNGD on their land. However, the owner of those minerals did sign a lease with an energy company. In PA, mineral rights supersede land rights, allowing UNGD to take place on the couple's land with or without their approval (Collins and Nkahsah 2013; Troutman 2011; PA DEP 2010). Twenty-three of their forty acres were used for well pads and access roads.

We sat in the dining room. An air scrubber ran, partially drowning out the sounds of earth-movers and construction equipment outside the home. Greta turned it off so that we could hear each other clearly. David described the feeling of ubiquity of UNGD and the impacts he

\footnotetext{
10 The CREATE Lab conducts a series of calibration protocols to ensure a level of validity and reliability by testing Specks against standardized PM monitoring tools, and against each other (Airviz 2015). The CREATE Lab calibrates Speck through a machine-based learning process with the Met-One HHPC6+ (MetOne), a handheld PM measuring approved by "ISO-14644 Clean Room Standards" by the International Organization for Standardization. An explanation of the Speck calibration process was shared on the citizen science and maker community, Publiclab.org_(Bartley 2014; CREATE 2014).

11 A recently published review of low-cost PM air monitors confirmed that the commercially available Speck can provide accurate PM measures over time and space, and that the tools can be used in tandem to provide exposure estimates when calibrated with one another (Manikonda et al. 2016).
} 
sees on the health of his neighbors, animals, and his own body. The couple's experience was at once economic, social, and physical: they had lost control over their property; their community was divided and friendships were broken because of disagreements about UNGD; and they saw their health deteriorating as a result of UNGD. He said:

\begin{abstract}
There are six or seven completed well sites within a mile of our place... They're drilling nine more wells on the hill right across from us... There are gonna be 23 wells within three quarters of a mile to a mile from our house... we kind of live in a basin because there are hills all around us, and most of these wells are on top of the hills, and any pollution that they are producing settles right in here... Four years ago my thyroid died, and the neighbor right across the road here-her thyroid died... now she has cancer all through her lymph nodes. Her two dogs got cancer and they died. Some of the other neighbors down the road-they have cancer. I know you can't just make a blanket statement saying that these Marcellus wells are causing all the problems here. But something is, that's the only thing that's new in the area. My adrenal glands just shut down this last winter. Something's causing this.
\end{abstract}

Suspecting exposures from nearby activities, but uncertain as to what their risks and outcomes might be, David and Greta used Speck to visualize PM and make immediate decisions. They left their home when readings were high. The Speck became a tool with immediate decision-making implications for the family and prompted them to address health concerns prior to receiving their overall analysis from EHP. As another user told us, the Speck is a device that "analyzes the particulates in the air, and tells you whether you're in a good range, a bad range, or 'head for the hills,' basically."

Daphne operates a childcare facility. Living in a former steel and coal town with growing UNGD infrastructure, Daphne has concerns about the cumulative impacts of industry. She observes her Speck throughout the day to make decisions for herself, her staff, and her children. When readings are high, she closes the windows and keeps the children inside in an attempt to limit exposures. When readings are low she keeps the windows open to allow the fresh air to flow inside. She watches the Speck throughout the day, noting its changes with the weather and making decisions accordingly. She says, "It has become a part of my life."

Daphne talks to parents of her daycare children about PM and attempts to use monitoring as an educational tool, noting the health of children and the multiple sources of pollutants. She often shares her results with the parents. She told us that she feels residents are unaware of often-imperceptible air pollution and that, in this case, "seeing is believing." While residents are accustomed to the sights, sounds, and smells of industry, the Speck quantifies and 
visualizes the emissions from these activities and provides new evidence for Daphne to take to her community.

Activist organizations in the area also employ the Speck as an environmental health thermometer to make real-time interventions. The Fracking Assistance Collective ${ }^{12}$ (FAC) sees itself as an emergency response team for health impacts associated with UNGD. Primarily, they fundraise and distribute resources to people impacted by UNGD. Just as a thermometer alerts an individual to the presence of a fever and the need for medical intervention, Specks in homes of residents alert FAC of the need for environmental health interventions. High readings prompt FAC to provide air scrubbers, conduct additional air sampling, and help residents navigate regulatory bureaucracies such as the PA Department of Environmental Protection. FAC uses the Speck's ability to fill knowledge gaps immediately in order to make real-time interventions without purchasing expensive devices or waiting on results from research studies.

Many reported looking at their Specks "all the time." They kept Specks in frequented places in the home, like bedrooms and living rooms. Here they could stay updated on their air quality throughout the day. The Speck is at once an educational tool and a tool for community action in this context, because while residents may suspect exposures, they remain uncertain about exactly when these exposures arise and how much risk they present. With the Speck and with instructions about the significance of PM readings from EHP, residents and organizations are able to put these exposures into a context for understanding risk and take immediate steps to address them.

\section{The Validator}

Other residents employed the Speck to explore and validate their exposure experiences and health impacts. These residents often used the Speck to monitor a specific UNGD process about which they had concerns (Allen 2003). The Speck became a useful aid to demonstrate their exposure experiences when their physical symptoms were ignored or discounted by other stakeholders: the industry, the state, and/or other community members. Chris used Specks collectively with his neighbors after they had experienced months of repeated exposure to fumes from a well pad. He told us about their experiences:

There's lots of gas releases, there's a lot of smells, a lot of fumes, an unbelievable amount of diesel fumes, and the residents have no way to know [the risks]... The release of the

12 The name of this organization has been changed to protect anonymity. 
natural gas liquids... and the release of the multiple components of $\mathrm{CH}$, methane being one of them, is a big concern. Sometimes you can smell them, sometimes you can just feel them, and you get headaches from them.

While residents may smell or feel exposures, acute pollutant releases across UNDG are both unmonitored at present and residents' symptoms are not counted as evidence by regulators. Chris considered appealing to the state's "Objectionable Odor Law," ${ }^{13}$ enforced by the WV Department of Air Quality (DAQ), which states: "No person shall cause, suffer, allow or permit the discharge of air pollutants which cause or contribute to an objectionable odor at any location occupied by the public" (3.1.) However, the method for determining an "objectionable odor" is illsuited to capturing UNGD emissions. DAQ personnel have discretion in defining an odor to be objectionable. However, UNGD emissions are inconsistent and unpredictable. Acute releases tend to dissipate between a resident's complaint and state agent's arrival to the scene. Without the DAQ's agreement that an odor exists, Chris's experiences are not authoritative. He says: "If [we] want to use things like [the] objectionable odor [law]... then an enforcement person from DAQ has to smell it themselves. It's not your nose, it's his nose that counts."

The Speck gave residents another way to document their experiences by taking snapshots of long-term and acute releases. Trudy plugged in her Specks after a gas processing plant near her home was struck by lightning and caught fire. Emergency services evacuated residents within a two-mile radius. As she hurried through the house in a panic, preparing to flee as thick black smoke spewed into the air, she plugged in her Speck to document the event. This was one of many "incidents" (as the company calls them) that occur at the plant. Trudy watches her monitor during suspected exposure events:

I like the fact that I know what's going on... Especially if there is anything as far as "incidents" go... At least it's giving you some kind of data that [the company] is not sharing with you... they keep telling us that it's all safe and that we're fine. It's hard to feel that way when you have all these different things going on where they evacuate people, and you see black smoke...

A lack of information about UNGD activities and suspicion of emission releases sparked engagement with the Speck. One resident told us that he checked it whenever he heard a new sound or a petrochemical smell coming from the well near his home, to confirm or deny his suspicions of exposure.

131967 WV Administrative Law Title 45, Series 04, 
Others used Specks to validate acute, embodied sensations of sickness. Six wells were recently constructed near Samantha's home (mentioned at the opening of this article). Her and her neighbors' water wells were contaminated after drilling began in 2012. One neighbor lost cows and his herd experienced reproductive problems. Multiple tests confirmed contamination in Samantha's well. She and her neighbors were given "water buffaloes"-large plastic containers of water to use for drinking, cooking, and bathing - by an active energy company in the area.

Samantha used the Speck to validate her suspicion of exposure. On one occasion, Samantha was outside and began to experience a sudden splitting headache, dizziness, and nausea. She described the feeling as akin to a stroke: "it was like, 'bang!'-all at once." Again, the Speck in her upstairs bedroom was red. Samantha's exposure experiences were confirmed in real time by the Speck. Participation helped Samantha to build on her sense of exposure and confirm her feelings of sickness. She thought that PEM data, including the Speck data, would be helpful for her own health and the health of her neighbors. She shared data with her doctor for the benefit of her own health and with her neighbors for the benefit of theirs. Validation was at once personal and political for Samantha. She says:

I'm gonna tell [my neighbor], “...get involved with EHP. Get those monitors to your house. You're closer to the wells. Think about your health..." He'll get these little groups together. He goes around. He'll tell them, "this is how it is. Go to this, do this." I'm gonna call him right after you leave.

While the Speck was used as a real-time validator, the data are also a tool of personal and political validation. Our surveys show that residents were often validated by their resultsmore than half of the respondents told us that their overall data were unsurprising-they confirmed suspicions.

While individual monitoring may make for individual outcomes, and EHP's Speck project is intended to be used for personal environmental health, it takes place within a broader social context of advocacy. In 2015, residents involved in a "nuisance suit" against an energy company operating in the region submitted Speck results as part of evidence of the disruption of their daily lives by UNGD. Maggie, a resident involved in the case, experienced sicknesses, lost animals, and feared for her health due to a series of exposure events: blowouts and venting near her home. After two years of complaints to the operator and WV DEP, the operator was ordered to stop venting gas. However, she says that after several months venting resumed. Her Specks showed high readings throughout the night. She expressed that it was validating to prove that 
she had been exposed to air pollutants when a company employee told her that the company did not ever vent gas near her home. Maggie said to the employee:

You know what? You guys are so full of crap. I already know. I have people coming in here. We have air monitors... We know what the hell's going on. The same time every night you're blowing this [gas] off. Don't tell me it's not happening-we know damn well it's happening!

Speck evidence has, in part, emboldened her to contest industry claims when she is faceto-face with employees and agents making statements that directly conflict with her experiences. Her results were used to confront the industry on the ground and will soon be used as evidence of a "nuisance" in the courts. Maggie did not need the tool to tell her that she was being exposed, but it became useful in validating her experiences to others.

\section{The "Epistemic Object"}

Others engaged with the Speck as an "epistemic object." These users took a critical, exploratory approach to the Speck and engaged with it, not as a finished product, but as a prototype with which to experiment on and assess its usefulness in the context of UNGD (Rheinberger 1997; Knorr Cetina 2001). They executed critical and experimental steps with the Speck to understand its limits and its usefulness in documenting exposures. Unlike others, who employed the Speck as a tool that could roughly and reliably prove objective exposure, these users saw the Speck as a black box that needed to be opened to understand its efficacy (Latour 1987).

Some of these users were active in other civic science projects related to UNGD and saw the Speck as a tool that might be useful in the context of their larger interests. For instance, Chris is a local expert-activist on the industry: he facilitates educational meetings among activists and residents to make sense of the complex processes of UNGD, and he has been documenting the expansion of the industry since the beginning of the boom in the region. Another user, Kent, is active in his own community's "watch group." He manages a website to monitor UNGD that he describes as a "radar screen." This involves documenting and mapping the industry's expansion in his community, and sending alerts about new activities. Kent, and others like him, worked with the Speck in an exploratory fashion as one of the many civic science activities they undertake to monitor UNGD.

EHP's Speck project may not be experimental in design, but for these users, the Speck is an opportunity to experiment. This group is concerned about what it can and cannot measure 
when placed in their homes, and they seek out the best ways to monitor UNGD. First theorized by Rheinberger (1997), Knorr Cetina (2001) describes epistemic objects as knowledge generating objects in fields of inquiry that are "unfolding, dispersed, and signifying (meaning producing)" (193). Users engaged in creative and experimental processes on the Speck to better suit their needs. These users took innovative steps in positioning of the Speck in hopes of achieving clearer results while simultaneously exploring the bounds of the device. When we asked Chris where he placed his Specks, he told us:

\begin{abstract}
Neither one was put in a home. Two of them were put under the eaves... the overhang of a house... We taped the two of them together-[another PM monitor] and the Speck. The other [Speck] was outside under a small gazebo... between two homes, rather than putting it on one or the other. Each home had different meteorological limitations because one was up, not too far away, but up in a valley so it's very possible that fumes could be coming up and noticed in the main valley but not at the home until later in the evening. So, airflow has a lot to do with whether you notice these things.
\end{abstract}

Users commonly took into consideration elevation and wind direction in the placement of their air monitors; many strategically placed their Speck in places that they hypothesized would catch more PM because of geophysical considerations in order to get a sense of the maximum PM exposure.

Kent literally opened the Speck—taking it apart to see what was inside—and worked to create his own air monitor based on what he found. He contacted CREATE to ask questions about the development of the monitor and discussed his plans for his own monitor. He had critical questions about the Speck; he pointed out that the sensor in the Speck had an inherent randomness in its readings of PM and wanted to know more about CREATE's algorithm that is used to correct randomness. He was uncertain about the impact of temperature, humidity, and turbulence on the Speck, and wanted to know more about these impacts. He told us that his hope was to use the Speck as a model to develop a monitor that could be used by his community to monitor UNGD sites and as a civic check on DEP inspections.

To residents who engaged with the Speck in strategic and creative ways, the Speck is an unbound "epistemic object" (Knorr Cetina 2001). Through this type of use individuals figured out for themselves what the Speck could and could not do, and the best uses for it in a climate of environmental uncertainty. These users wanted to understand the efficacy of the seemingly simple box before them and engaged in different experimental observations to do so. They did 
not wait for expert data to define their exposures, they engaged in their own science to best understand their exposures.

\section{Passive Use}

We don't intend to overemphasize the relevance of PEM in the lives of participants. Many didn't see the Speck as an experimental object; many did not observe the Speck throughout the day to see if its readings coincided with their embodied experiences; and many did not make real-time decisions based on readings. Some let the Speck collect PM data, sent the Speck back to EHP, and waited for the results.

Burdened by everyday stresses, overwhelmed by UNGD and health concerns, and/or burnt out on activism, residents who use the Speck are presented with yet another technical process to interpret. The presence of the Speck is a reminder of an atmosphere of uncertainty, and residents may feel as though the Speck is another emerging technology with uncertain implications. The first Speck prototype did not place air quality into the context of the EPA air quality index (AQI), the federal standard of healthy air quality, and users may have felt unable to simply interpret the results for themselves. Further, feeling abandoned by state regulatory agencies and as afterthoughts for industry, residents may feel ambivalent about being tasked with doing their own air monitoring.

Passive-use of the Speck may be related to the experiences of exposure and the temporal nature of UNGD. For example, one resident was concerned about the ongoing expansion of UNGD around her home. However, while she had the Speck, these activities were at a standstill. A well was drilled but extraction activities had yet to begin. When I asked if she looked at the Speck she said:

No. Sorry. I just plugged it in and I looked a couple of times. It was always really low numbers in the single or double digits and a couple times I saw that it was kind of high like 200 or 300 [counts $\left./ \mathrm{m}^{3}\right] \ldots$ I knew it was recording its own data so I didn't.

Lack of UNGD activity, timing of exposures, and low readings may explain why this user didn't engage actively with the Speck. Perhaps high readings would have prompted a more participatory approach to monitoring or participation with the data after monitoring. During monitoring, many users did not feel it was their place or obligation to interfere with the Speck processes, and did not have any desire to pay attention to real-time readings. This could be a function of the exposure experience. 
Forgetting about the Speck's presence, choosing not to interact with the device, or not sharing the data is a personal choice-one that the design of EHP's project engenders. Many of these users were more interested in long-term data than acute readings while they had Specks. In fact, for some, the lack of interaction necessary to collect data was seen as a positive. Some told us about their past use of other monitoring devices that required a great deal of interaction and became overly burdensome. Others engaged in other PEM like stream monitoring and water sampling, but had trouble recruiting others to take part in these time-intensive activities. They were happy for a simple environmental sensor. Harrison (2011) shows that community participation in overly time-consuming and complex environmental health monitoring can become burdensome. A resident and an organizer told us, "You need something like [the Speck] where you plug it in, and walk away. And that's what you achieved, so that's a great value."

\section{From Individual Data to Civic Science}

The "great value" described above depends on organizations like EHP doing something with the resulting data. Engaging in, rather than being thwarted by the uncertainties abounding in the monitoring effort, EHP has used data from these Specks to make novel scientific contributions to the study of UNGD. While resident's rarely have the time and capacity to develop scientific publications, EHP has built a network of scientists equipped to analyze the Speck data, such as environmental public health scientist and toxicologist Dave Brown, $\mathrm{ScD}$, the former Chief of Environmental Epidemiology and Occupational Health in Connecticut, Associate Professor of Toxicology at Northeastern College of Pharmacy and Allied Health, and former Deputy Director of the Public Health Practice Group of Agency for Toxic Substances and Disease Registry (ATSDR).

Brown and colleagues' analysis of PM data made plain the inadequacy of EPA use of average PM data as indicative of actual exposures. EPA measurements of air pollution, including $\mathrm{PM}_{2.5}$, base air quality only on averages rather than focusing on episodic exposures and variability throughout the day (Brown et al. 2015; Brown et al. 2014, 12). Averaging measurements and focusing on the 24-hour median level of $\mathrm{PM}_{2.5}$ washes out dramatic spikes in exposure throughout the day. For instance, in Figure 1 (Table 4), Brown et al. (2014) show that in House 7, located near an UNGD site, $\mathrm{PM}_{2.5}$ counts peaked to unhealthy levels 31 times over a period of roughly two weeks and reached a high of 1654 counts / feet. ${ }^{3}$ However, the median $\mathrm{PM}_{2.5}$ level for the home was just 38 counts/feet ${ }^{3}$. This, according to the EPA, is healthy air, 
though residents are exposed to unsafe levels of $\mathrm{PM}_{2.5}$ over 30 times over a period of roughly two weeks (Brown et al. 2014).

Table 4 Peak $\mathrm{PM}_{2.5}$ count values for each house, number of hours, \% total hours, times of day, and maximum peak value (counts/0.01 cubic feet).

\begin{tabular}{rrrrrr}
\hline House & $\begin{array}{r}\text { Number of } \\
\text { hours with } \\
\text { peaks }\end{array}$ & $\begin{array}{r}\text { \% of total Times of } \\
\text { hours with day of } \\
\text { peaks } \text { peaks }\end{array}$ & $\begin{array}{r}\text { Maximum } \\
\text { peak value } \\
\text { of PM } \\
\text { counts }\end{array}$ & $\begin{array}{r}\text { Median } \\
\text { value } \\
\text { of PM }\end{array}$ \\
counts \\
\hline 1 & 12 & 8.5 N & 2711 & 54 \\
2 & 11 & 5 M, N & 756 & 65 \\
3 & 3 & 2.5 M & 171 & 40 \\
4 & 1 & 0.5 N & 201 & 4 \\
5 & 8 & 2.5 A, E & 556 & 51 \\
6 & 11 & 7.7 A, E, N & 576 & 45 \\
7 & 31 & 8.7 M, A, E & 1654 & 38 \\
8 & 29 & 15 M, A, E & 991 & 30 \\
9 & 9 & 12.6 M, E, N & 1057 & 69 \\
10 & 23 & 32 M, A, E, N & 844 & 75 \\
11 & 7 & 16 M, E & 3846 & 49 \\
12 & 2 & 1.4 E & 203 & 57 \\
13 & 3 & 4.3 M & 164 & 38 \\
14 & 57 & 34.3 M, A, E, N & 1761 & 78 \\
\hline
\end{tabular}

aTimes of day: Morning: 6:00 a.m. to 12 noon; Afternoon: 12 noon to 6:00 p.m.; Evening: 6:00 p.m. to 12 midnight; Night: 12 midnight to 6:00 a.m.

Figure 2: Table showing PM2.5 peaks and averages across homes (Brown et al. 2014). 
Brown et al. 2015 further demonstrates the problem of averaging out air quality by developing a model for understanding episodic peaks in PM from multiple UNGD sources in Washington County, PA. EHP researchers developed the model based on a hypothetical home (typical of many residences involved in the Speck project) exposed to numerous intermittent sources of air pollution associated with UNGD. Using reported DEP air emissions data and atmospheric data, EHP developed an air quality model that shows how homes in southwest PA are exposed to unhealthy peaks of VOCs and PM from multiple, intermittent sources mediated by atmospheric conditions and distance between residence and UNGD process. Their findings suggest the need for continuous monitoring and the need to assess air quality based on 6-hour windows rather than 24-hour averages when considering health outcomes from residential exposures to UNGD. Figure 2 (Table 7 ) shows that both thresholds and maximum values of frequent peaks are far higher than average PM releases across multiple UNGD processes (Brown et al. 2015).

Table 7. Average intensities and peak values of PM peaks are defined as 2 standard deviations above the mean, in 6 -h increments.

\begin{tabular}{lcccc}
\hline UNGD Source & Average Intensity & Threshold of Peak Value & Maximum 6-h Peak Value & Frequency of f-h Peaks \\
\hline Drilling & 6 & 37 & 140 & $26 / 5$ months \\
Hydr. fracturing & 4 & 26 & 56 & $2 / 15$ days \\
Flaring/finishing & 6 & 39 & 116 & $30 / 5$ months \\
Producing & 6 & 39 & 128 & $25 / 3$ months \\
Compressor & 3 & 23 & 56 & $118 / 1$ year \\
Proc. Station & 19 & 106 & 150 & $99 / 1$ year \\
\hline
\end{tabular}

"This represents the minimum value that is considered a "peak" - defined as 2 standard deviations above the mean. Maximum peak values represent the highest peaks found in the analysis. All values are in ug $\mathrm{m}^{-3}$.

Figure 3: Table showing PM Peak Values across UNGD sources (Brown et al. 2015).

While there is a good argument to be made that the burden of environmental monitoring should not be passed onto the general public, EHP's distributed sensing with the Specks made evident problems at people's homes that are unlikely to be captured conventionally. Residents in EHP's project decided what to do with their data and, through the 
partnership with EHP, received useable data and contributed to developing collective knowledge of the impacts of UNGD.

Although the Speck is itself a consumer product, marketed towards individuals who are concerned with personal exposures in their homes, when the monitor and its data are utilized within EHP's model, users can move from individualized to civic engagement. EHP and the Speck project exist within a network of neighborhood groups, CBOs, and non-profits in the region. At least 14 organizations working to collect and understand information about the environmental health impacts of UNGD, responding to these impacts through political activism and legal advocacy work, as well as assisting fence line residents, have engaged with EHP's Speck air monitoring project. This includes using the Speck and air quality data for advocacy, connecting impacted residents to EHP and the Speck, distributing EHP materials about air quality and health, and hosting EHP at group meetings and events. Members of national conservation organizations, citizen science initiatives, local environmental justice organizations, national civic organizations, and neighborhood grassroots groups have learned about their air quality through engaging with the Speck, and EHP serves as a resource to supplement groups' activities and assist the communities with whom they engage.

Increasingly, Speck data are collected in partnership with $\mathrm{CBOs}$ to contest industry expansion. In 2014, a grassroots organization Minisink Matters (MM), located in Sullivan County, NY, approached EHP for assistance in determining whether the emissions from a nearby compressor station were responsible for health impacts families members were experiencing. The group had initially opposed the construction of this facility but were unable to halt its construction. EHP placed five Speck monitors in residences near the compressor for two months, collected health information from eight families living within 1.5 kilometers of the site, and supported residents' efforts to collect VOC samples in four locations (Environmental Health Project 2015).

EHP documented episodic neurological, respiratory, and dermatological symptoms across each family involved in the study. Speck monitoring revealed simultaneous unhealthy episodic spikes in $\mathrm{PM}_{2.5}$ across monitors. According to Figure 3: on November 12, four of five monitors detected spikes in PM between 53.7 and $325 \mathrm{ug} / \mathrm{m}^{3}$ - considerably unhealthy levels of PM. However, the average AQI on November 12 was $9 \mathrm{ug} / \mathrm{m}^{3}$-air quality considered officially healthy-further demonstrating the lived experiences of unhealthy exposure that become hidden in 24-hour averages. 


\begin{tabular}{|l|c|r|r|}
\hline $\begin{array}{c}\text { Date of } \\
\text { Peak } \\
\text { event }\end{array}$ & $\begin{array}{c}\text { \# of monitors } \\
\text { showing } \\
\text { a peak out of \# in use }\end{array}$ & $\begin{array}{c}\text { Recorded peak } \\
\text { levels }\end{array}$ & $\begin{array}{c}\text { Daily } \\
\text { AQI } \\
\text { average }\end{array}$ \\
\hline $10 / 30$ & $3 / 4$ & $31,90,426$ & 5.0 \\
\hline $11 / 5$ & $2 / 5$ & 33,57 & 5.5 \\
\hline $11 / 7$ & $3 / 5$ & $36.5,114,133$ & 5.3 \\
\hline $11 / 12$ & $4 / 5$ & $43,235,399$ & 5.0 \\
\hline $12 / 3$ & $3 / 5$ & 76,160 & 10.8 \\
\hline $12 / 6$ & $2 / 5$ & $99,162,229$ & 9.9 \\
\hline $12 / 17$ & $3 / 5$ & & 9.0 \\
\hline
\end{tabular}

Figure 4: Table showing PM Readings across Monitors in Minisink, NY (Environmental Health Project 2015).

The Minisink report has generated interest both in the potential harm from compressor station emissions and the use of Specks in organized community data collection projects. Since its completion, five counties in NY and two in PA have organized projects using the same protocol including Specks. The report has garnered media attention and was used to contest the proposed development of UNGD infrastructure in other Sullivan County towns, prompting some town boards to draft resolutions opposing compressor stations within the county (Mayer 2016; Times Herald-Record 2016; Cohen 2015). The case illustrates the ability of EHP to shift and update its protocols in order to remain flexible in response to specific community needs and to directly engage with politically-active $\mathrm{CBOs}$, something that may prove challenging in other traditional academic research-based models. Further, the case shows the civic and political outcomes that might come from community engagement in PEM projects within an organized network of scientific experts, advocates, and CBOs like the one maintained by EHP.

\section{Conclusion}

In summary, the structure of EHP's Speck research project afforded participants flexibility in how they engaged in research. Through semi structured interviews and qualitative surveys, we show that the Speck was used in four varying, but not mutually exclusive ways: 1) as an environmental health thermometer showing real time PM measurements; 2) as a validator 
corroborating the exposure experiences of the user; 3) as an epistemic object used in exploratory civic science; and 4) the Speck project was passively engaged by some users. For those who needed it, it provided immediately useful data; for others it helped validate their daily experiences of exposure by providing external visible evidence. The Speck additionally gave some the opportunity to become experimenters themselves, evolving their own research projects, while for others it simply functioned as an unobtrusive object that didn't impinge on their daily lives by requiring too much attention. While affording this range of experience and modes of participation, when connected with EHP the Speck data also provided grounds for new scientific findings and advocacy work. EHP'S Speck project thereby provides an important new model for responsive research that occurs amidst the uncertainty of emergent environmental health hazards and is suited the contemporary era: one that adds real-time monitoring to the Three R's of Residency, Research and Reform. Real-time results in this case provided immediately useful grassroots data that are still amenable to aggregated analysis by experts.

Citizen science projects, including PEM, have been critiqued as neoliberal shifts of responsibility for environmental crises from industry and governments to the general public (Kinchy et al. 2012; Steinberg 2010). The Speck alone, as a consumer product, is designed for individualized use, and by itself, may not present a challenge or critique to the fast-paced UNGD boom in the Marcellus shale or the policies that support it. However, as we show here, when connected with public health organizations like EHP and activist communities in the region, the Speck project can both increase individual's agency to challenge the UNGD boom and facilitate the production of collective knowledge by producing novel and accessible scientific findings. The development and maintenance of this knowledge may be more critical than ever as US energy policy shifts further toward the facilitation of the expansion of UNGD and fossil fuel development projects (Phillips and Hurdle 2017). One characteristic of this shift is the further weakening of emission monitoring and reporting as the Trump administration seeks to repeal Obama-era requirements on the oil and gas industry to report methane emissions to the EPA (Lavelle 2017). The proposed increase in UNGD activity in Trump's "America-First Energy Plan" (White House 2017), coupled with a decrease in monitoring and reporting, further obscures the cumulative impacts of air pollution from UNGD and signals an urgent need for community-driven action. A well-organized network of scientists, activists, advocates, residents, and researchers, working with accessible tools like the Speck, can provide collective knowledge that counters the obscurity created by a deregulated UNGD boom, while simultaneously increasing the political agency of communities on the ground. 
This thematic collection investigates how Science and Technology Studies research can reshape the object of critique. Lead author Jacob Matz, who conducted the interviews, shared his analysis, interviews, survey results, and field notes with EHP throughout the course of the project. The classificatory framework for participation helped EHP evaluate their PEM project and created a useful record of how participants made use of the data and devices. This allowed EHP to ask key questions about how to respond and engage with each "type" of participation, including:

1) If the Speck is used as an "environmental health thermometer," then what are sustainable steps for real-time individual environmental health intervention?

2) When used as a "validator," how can EHP track and make sense of incidences of exposure felt by residents and validated by the presence of Speck monitors?

3) How can EHP productively engage with users who are comfortable with experimenting with the device and testing their own hypotheses based on first-hand experience?

4) Are there benefits to moving residents from the status of passive users to more active roles in the Speck (and other PEM) project(s)?

This paper has provided specific implications for EHP's Speck project, and its findings can be taken into consideration in the design of future PEM projects in the region. The process of academic collaboration focused on learning about users' experiences in an ongoing PEM project should also be exported to other civic science projects. CBOs rarely have the time for such retrospective study and analysis. Their partnership in this research shows how engagement with STS research can assist both the organizations and the researchers in developing and maintaining robust participation in civic science.

\section{Author Biography}

Jacob Matz received a Master's degree in Sociology from West Virginia University in 2013. He was a graduate research assistant at Northeastern University in the Social Science Environmental Health Research Institute (SSEHRI) and the Department of Sociology and Anthropology. His research interests include environmental justice, community-based 
participatory research, and the politics of extractive industries. Matz has co-authored peerreviewed publications in Environmental Communication: A Journal of Nature and Culture, The Hastings Center Report, Sociological Focus, and New Solutions: A Journal of Environmental and Occupational Health Policy.

\section{Author Biography}

Sara Wylie is an Assistant Professor of Sociology/Anthropology and Health Sciences in Northeastern University's Social Science Environmental Health Research Institute. Wylie is a cofounder of Public Lab and EDGI, the Environmental Data and Governance Initiative. Wylie seeks to develop research tools, collaborations and platforms for studying and creating accountability for the fossil fuel and allied petrochemical industries. She has a forthcoming book with Duke University Press on the U.S. boom in unconventional energy production titled: Fractivism: Corporate Bodies and Chemical Bonds.

\section{Author Biography}

Jill Kriesky is the Associate Director of the Southwest Pennsylvania Environmental Health Project (EHP) located in Washington County, PA. EHP's mission is to provide residents of communities impacted by unconventional oil and gas development (UOGD) with accurate, timely, and trusted information about its health impacts. Kriesky's roles at EHP include devising ways to integrate community interests and academic activity on UOGD topics through research collaborations and internships and developing its Shale Gas and Oil Health Registry and Resource Network.

\section{Acknowledgements}

The authors would like to acknowledge and thank the graduate students and faculty at the Social Science Environmental Health Research Institute (SSEHRI) for their thoughtful insight throughout each step of the research process. We would also like to thank the team at the South West Pennsylvania Environmental Health Project for accommodating this collaboration. Lastly, we would like to acknowledge the team at the CREATE Lab at Carnegie Mellon University for their willingness to share detailed explanations of the Speck. 


\section{References}

Adams, Crystal, P. Brown, R. Morello-Frosch, J.G. Brody, R.A. Rudel, A. Zota, S. Dunagan, J. Tovar,and S. Patton. 2011. "Disentangling the Exposure Experience: The Roles of Community Context and Report-back of Environmental Exposure Data." Journal of Health and Social Behavior 52(2):180-196.

Addams, Jane. 1892. "A New Impulse to an Old Gospel," Forum, XIV (Nov.): 350, 351

Adgate, John L., B.G Goldstein, and L.M. McKenzie. 2014. "Potential Public Health Hazards, Exposures and Health Effects from Unconventional Natural Gas Development." Environmental Science and Technology 48(15):8307-8320.

Allen, B. 2003. Uneasy Alchemy: Citizens and Experts in Louisiana's Chemical Corridor Disputes. Cambridge, MA: MIT Press.

Airviz. 2015. “Indoor Performance Testing Results December, 2015." Accessed 7 August 2016: https:// www.specksensor.com/docs/learn/speck indoor performance testing.pdf

Airviz. 2015. Speck Homepage. Accessed1 December 2014 from: http: / / www.specksensor.org

Amico, C., D. DeBelius, S. Detrow, and M. Stiles. 2014. “Shale Play: Natural Gas Fracking in Pennsylvania." Accessed 1 December 2014. http://stateimpact. npr.org/pennsylvania/ drilling/.

Altman, Rebecca Gasior, R. Morello-Frosch, J.G. Brody, R.A. Rudel, P. Brown, and M. Averick. 2008. "Pollution Comes Home and Gets Personal: Women's Experience of Household Chemical Exposure." Journal of Health and Social Behavior 49:417-435.

Auyero, Javier and D. Swistun. 2007. "Confused because exposed: Towards an ethnography of environmental suffering." Ethnography 8(2):123-144.

Bamberger, Michelle, and R. Oswald. 2012. "Impacts of gas drilling on human and animal health." Solutions Journal of Environmental Occupational Health Policy NS 22(1):51-77.

Bartley, C. 2014. Speck Particle Monitor. PublicLab.org Accessed 7 August 2016. https:// publiclab.org/notes/chrisbartley/04-15-2014/speck-particle-monitor

Beck, U. 1992. Risk Society: Towards a New Modernity. London: Sage.

Bolden, Ashley, C. Kwiatkowski, C., T. Colborn. 2015. “New look at BTEX: are ambient levels a problem?" Environmental Science and Technology 49(9): 5261-5276.

Briggle, A. 2015. A Field Philosopher's Guide to Fracking. New York: Liveright.

Brown, David B.I. Weinberger, C. Lewis, and H. Bonaparte. 2014. "Understanding exposure from natural gas drilling puts current air standards to the test." Reviews on Environmental Health 29(4):277-92. 
Brown, David, C. Lewis, and B.I. Weinberger. 2015. "Human exposure to unconventional natural gas development: A public health demonstration of periodic high exposure to chemical mixtures in ambient air." Journal of Environmental Science and Health, Part A 50: 460-472.

Carlton, Annmarie G., E. Little, M. Moeller, S. Odoyo, and P.B. Shepson. 2014. "The Data Gap: Can a Lack of Monitors Obscure Loss of Clean Air Act Benefits in Fracking Areas?" Environmental Science and Technology. 48(2): 893-894.

Churg, Andrew, M. Brauer, M. del Carmen Avila-Casado, T.I., Fortoul, and J.L. Wright. 2003. "Chronic exposure to high levels of particulate air pollution and small airway remodeling." Environmental Health Perspectives. 111(5): 714-718.

Cohen, J. 2015. "Gas Compressors and Nose Bleeds: A new study connects health issues with rural gas compressor pollution." Utne Reader. Fall 2015. Accessed online: http:// www.utne.com/environment/gas-compressors-and-nose-bleeds-zm0z15fzsau.aspx

Colborn, Theo, C. Kwiatkowski, K. Schultz, and M. Bachran.2011. Natural gas Operations from a Public Health Perspective. Human and Ecological Risk Assessment: An International Journal 17(5):1039-1056.

Colborn, Theo, K. Schultz, L. Herrick, and C. Kwiatkowski. 2014. "An Exploratory Study of Air Quality Near Natural Gas Operations." Human and Ecological Risk Assessment 20:86-105.

Collins, Alan. R. and K. Nkansah. 2013. “Divided rights, expanded conflict: the impact of split estates in natural gas production." Paper Presented at the Agricultural and Applied Economics Association Annual Meeting, Washington, DC, August 5, 2013.

Corburn, J. 2005. Street Science: community knowledge and environmental health justice. Cambridge MA: MIT Press.

CREATE. 2014. “Carnegie Mellon CREATE Lab - About us.” Accessed 1 December 2014.: http:// www.cmucreatelab.org/about

DeFranco, Emily, W. Moravec, F. Xu, E. Hall, M. Hossain, E.N. Haynes, L. Muglia, and A. Chen. 2016. "Exposure to airborne particulate matter during pregnancy is associated with preterm birth: a population-based cohort study." Environmental Health. Published online January 15, 2016.

Dominici, Francesca, R.D. Peng, M.L. Bell, L. Pham, A. McDermott, Aidan, S.L. Zeger, and J.M. Samet. 2006. "Fine Particulate Air Pollution and Hospital Admission for Cardiovascular and Respiratory Diseases." Journal of the American Medical Association 295(10):1127-1134.

Edelstein, M. R. 1988. Contaminated communities: The social and psychological impacts of residential toxic exposure. Boulder: Westview Press. 
EPA. 2003. What is Particle Pollution? Office of Air and Radiation. EPA-452/F-03-001. Accessed 20 February 2016.

http: / / www3.epa.gov / airquality / particlepollution/pdfs/ pm-color.pdf

EPA. 2013. "Particulate Matter (PM): Fast Facts." Accessed 30 October 2014. http:// www.epa.gov/ airquality/particulatematter/fastfacts.html.

EPA. 2014. “Particulate Matter (PM): Health.” Accessed 30 October 2014. http:/ / www.epa.gov/ airquality/particulatematter/health.html.

Follett R, Strezov V. 2015. “An Analysis of Citizen Science Based Research: Usage and Publication Patterns." PLoS ONE 10(11): e0143687. doi: 10.1371/journal.pone.0143687

Fortun, Kim and M. Fortun. 2005. Scientific Imaginaries and Ethical Plateaus in

Contemporary U.S. Toxicology. American Anthropologist. 107(1): 43-54.

Graham, John.2011. "Fine Particulate Matter $\left(\mathrm{PM}_{2.5}\right)$ and Ozone $\left(\mathrm{O}_{3}\right)$ Air Quality in Western Pennsylvania in the 2000s." Clean Air Task Force, March 9.

Gullion, J.S. 2015. Fracking the Neighborhood: Reluctant Activists and Natural Gas Drilling. Cambridge MA: MIT.

Harrison, Jill. 2011. "Parsing 'participation' in action research: Navigating the challenges of lay involvement in technically complex participatory science projects." Society and Natural Resources 24, 702-716.

Hays, Jake and S.B.C. Shonkoff. 2016. “Toward an Understanding of the Environmental and Public Health Impacts of Unconventional Natural Gas Development: A Categorical Assessment of the Peer-Reviewed Scientific Literature, 2009-2015." PLoS ONE 11(4): e0154164.

Israel, Barbara A., A.J Schulz, E.A. Parker, and A. Becker. 1998. "Review of Community-Based Research: Assessing Partnership Approaches to Improve Public Health." Annual Review of Public Health 19: 173-202.

Jalbert, Kirk, A.J. Kinchy, and S.L. Perry. 2014. "Civil society research and Marcellus Shale natural gas development: results of a survey of volunteer water monitoring organizations." Journal of Environmental Studies of Science 4: 78-86.

Kinchy, Abby J. and S.L. Perry. 2012. "Can Volunteers Pick up the Slack? Efforts to Fill Knowledge Gaps about the Watershed Effects of Marcellus Shale Gas Development." Duke Environmental Law and Policy Forum 22(2): 303-340.

Kinchy, Abby, K. Jalbert, and J. Lyons. 2014. "What is volunteer water monitoring good for? Fracking and the plural logics of participatory science." Political Power and Social Theory 27:259-289. 
Knorr Cetina, K. 2001. "Objectual practice” The Practice Turn in Contemporary Theory. Edited by T. Schatzki, K. Knorr Cetina, and E. Von Savigny. London and New York: Routlidge.

Kosnik, R.L. 2007. The Oil and Gas Industry's Exemptions to Major Environmental Statues. Earthworks Oil and Gas Accountability Project. Accessed 7 August 2016. http:// www.shalegas.energy.gov/resources / 060211_earthworks_petroleumexemptions.pdf

Kriesky, J. 2015. SWPA-EHP's Approach to Protecting Health through Emissions Monitoring. Presentation to Society for Applied Anthropology Annual Meeting, Pittsburgh, PA March 24, 2015.

Lampe, David J. and J.F. Stolz. 2015. "Current perspectives on unconventional shale gas extraction in the Appalachian Basin." Journal of Environmental Science and Health, Part A: Toxic/Hazardous Substances and Environmental Engineering. 50(5): 434-446.

Latour, B. 1987. Science in Action: How to follow scientists and engineers through society. Cambridge, MA: Harvard Press. Cambridge.

Lavelle, M. 2017. “Trump's EPA Halts Request for Methane Information From Oil and Gas Producers." InsideClimate News. Accessed 19 July 2017: https://insideclimatenews.org/ news/03032017/ scott-pruitt-environmental-protection-agency-methane-greenhousegas-climate-change

Macey, Gregg P., R. Breech, M. Chernaik, C. Cox, D. Larson, D. Thomas, and D.O. Carpenter. 2014. "Air concentrations of volatile compounds near oil and gas production: a community-based exploratory study." Environmental Health 13:82. http:// www.ehjournal.net/content/13/1/82

Manikonda, Abhisek, N. Zikova, P.K. Hopke, and A.R. Ferro. 2016. Laboratory assessment of low-cost PM monitors. Journal of Aerosol Science. 102: 29-40.

Marino, Elisa, M. Caruso, D. Campagna, and R. Polosa.2015. "Impact of air quality on lung health: myth or reality?" Therapeutic Advances in Chronic Disease. 6(5): 286-298.

Mayer, F. 2016. "Backlash against Highland Compressor Station; County may join towns in opposing gas infrastructure." The River Reporter. February 12.. Accessed 7 August 2016. http: / / www.riverreporter.com/news/14/2016/02/12/backlash-against-highlandcompressor-station-county-may-join-towns-opposing-gas-i

McGraw, S. 2012. The End of Country: Dispatches from the Frack Zone. New York: Random House.

Minkler, Meredith., A.P. Garcia, V. Rubin, and N. Wallerstein. 2010. "Community-Based Participatory Research: A Strategy for Building Healthy Communities and Promoting Health through Policy Change." PolicyLink. 
Minkler, Meredith and N. Wallerstein, 2003. "Introduction to Community Based Participatory Research. In, Community Based Participatory Research for Health." Edited by Minkler, M. and Wallerstein, N. San Francisco, CA: Jossey Bass.

Murphy, M. 2006. Sick Building Syndrome and the Problem of Uncertainty: Environmental Politics, Technoscience, and Women Workers. Durham: Duke University Press.

Nel, André. 2005. “Air Pollution-Related Illness: Effects of Particles.” Science 308(5723): 804-806.

Nemmar, Abderrahim, P.H. Hoet , B. Vanquickenborne, D. Dinsdale, M. Thomeer, M.F. Hoylaerts, H. Vanbilloen, L. Mortelmans, B. Nemery. 2002. "Passage of inhaled particles into the blood circulation in humans." Circulation 105(4): 411-414.

PA DEP. 2010. "Landowners and Oil and Gas Leases in Pennsylvania." Pennsylvania Department of Environmental Protection. Accessed 7 August 2016: https:// www.documentcloud.org/documents/358469-landowner-rights.html

Page-Jacobs, L. 2015. "A home air quality monitor that can be checked out from the library." National Public Radio. May 24. Accessed 7 August 2016: http://www.npr.org/ 2015/05/24/408786881/a-home-air-quality-monitor-that-can-be-checked-out-from-thelibrary

Perry, Simona. 2012. "Development, land use, and collective trauma: The Marcellus shale gas boom in rural Pennsylvania." Culture, Agriculture, Food and Environment 34(1):81-92.

Phillips S. and J. Hurdle. 2017. President Trump's energy plan: support shale, dump climate plan, refocus EPA. StateImpact. Accessed 19 July 2017: https://stateimpact.npr.org/ pennsylvania / 2017 / 01/20 / president-trumps-energy-plan-support-shale-dump-climateplan-refocus-epa/

Raaschou-Nielsen, Ole, Z. J. Andersen, R. Beelen, E. Samoli, M. Stafoggia, G. Weinmayr, B. Hoffman et al. 2013. "Air pollution and lung cancer incidence in 17 European cohorts: prospective analyses from the European Study of Cohorts for Air Pollution Effects (ESCAPE)." The Lancet Oncology 14(9): 813-822.

Rabinowitz, Peter M., I.B. Slizovskiy, V. Lamers, S.J. Trufan, T.R. Holford, J.D.Dziura, P.N. Peduzzi, M.J. Kane, J.S Reif, T.R. Weiss, and M.H. Stowe. 2014. “Proximity to Natural Gas Wells and Reported Health Status: Results of a Household Survey in Washington County, Pennsylvania." Environmental Health Perspectives 123(1): 21-26.

Rheinberger, H.J. 1997. Toward a History of Epistemic Things: Sythesizing Proteins in the Test Tube. Palo Alto: Stanford University Press.

Rich, Richard C., M. Edelstein, W. K. Hallman, and A. H. Wandersman. 1995. Citizen participation and empowerment: The case of local environmental hazards. American 
Journal of Community Psychology 23(5): 657-676.Rouvalis, C. 2015. Gadgets and Gizmos and Community Gains. H: the magazine of the Heinz Endowments. (1). Accessed 7 August 2016: http:// www.heinz.org/UserFiles/Library/2015 Issue1 Gadgets-2.pdf

Schmidt, Charles. 2011. "Blind Rush? Shale Gas Boom Proceeds Amid Human Health Questions." Environmental Health Perspectives 119(8): a348-a353.

Sellers, C. 1997. Hazards of the Job: From Industrial Disease to Environmental Health Science. Chapel Hill, NC: University of North Carolina Press.

Shonkoff, Seth B.C., J. Hays, and M. L. Finkel. 2014. “Environmental Public Health Dimensions of Shale and Tight Gas Development." Environmental Health Perspectives 22(8).

Southwest Pennsylvania Environmental Health Project (EHP) (2014). Accessed 1 December 2014: http:/ / www.environmentalhealthproject.org/

Southwest Pennsylvania Environmental Health Project (EHP). 2015. "The Southwest Pennsylvania Environmental Health Project Procedure for air quality monitoring and analysis using Speck PM2.5 monitors." Accessed 7 August 2016: http:// www.environmentalhealthproject.org/files/Protocol-for-Speck-monitoring.pdf

Southwest Pennsylvania Environmental Health Project (EHP). 2015. "Summary of Minisink compressor station monitoring results." Accessed 7 August 2016: http:// www.environmentalhealthproject.org/resources $/ 3 /$ click $/ 5$

Spice, B. 2015. “Carnegie Mellon Spinoff Introduces Speck, a Personal, Wi-Fi-Connected Air Quality Monitor." Carnegie Mellon University News. Accessed 19 July 2017: https:// www.cmu.edu/news/stories/archives/2015/march/speck-air-quality-monitor.html

Steinberg, Ted. 2010. "Can Capitalism Save the Planet?: On the Origins of Green Liberalism." Radical history review (107):7-24.

Steinzor, Nadia, W. Subra, and L. Sumi. 2013. "Investigating links between shale gas development and health impacts through a community survey project in Pennsylvania." New Solutions 23(1):55-83.

Stieb, David, L. Chen, B. S. Beckerman, M. Jerrett, D. L. Crouse, D. W. Rasugu Omariba, P. A. Peters, A. van Donkelaar, et al. 2016. "Associations of Pregnancy Outcomes and $\mathrm{PM}_{2.5}$ in a National Canadian Study." Environmental Health Perspectives 124(2).

Subra, Wilma. 2012. "Human health impacts associated with chemicals and pathways of exposure from the development of shale gas plays." Presentation. August 2012. EARTHWORKS Oil and Gas Accountability Project.

Szasz, A. 2007. Shopping our way to safety. Minneapolis: University of Minnesota Press. 
Times Herald-Record. 2016. Highland board against compressor station. Times Herald-Record. Accessed online 4 August 2016: http://www.recordonline.com/article/20160210/ NEWS/160219900

Troutman, M. 2011. "Property Owner Loses Land to Natural Gas Company on Split Estate." Public Herald. Accessed 7 August 2016: http://publicherald.org/barndt/201106/

Wade. Louise C. 1967. "The Heritage from Chicago's Early Settlement Houses.” Journal of the Illinois State Historical Society 60:4, 411-441.

Werner, Angela K., S. Vink, K. Watt, and P. Jagals. 2015. "Environmental health impacts of unconventional natural gas development: A review of the current strength of evidence." Science of the Total Environment 505:1127-1141.

White House. 2017. “An America First Energy Plan.” The White House. Accessed 19 July 2017: https://www.whitehouse.gov/america-first-energy

Williams, Ron, A. Kaufman, T. Hanley, J. Rice, , and S. Garvey. 2014. "Evaluation of FieldDeployed Low Cost PM sensors. Office of Research and Development." National Exposure Research Laboratory. EPA/600/R-14/464. December 2014.

World Health Organization (WHO). 2013. Health effects of particulate matter: policy implications for countries in Eastern Europe, Caucasus and central Asia. Regional Office for Europe. Accessed 7 August 2016.: http://www.euro.who.int/ data/assets/ pdf file/0006/189051/Health-effects-of-particulate-matter-final-Eng.pdf

WV Administrative Law Title 45, Series 04. Effective date: October 1, 1967. §22-5-1 et seq. Accessed7 August 10, 2016: https://apps.sos.wv.gov/adlaw/csr/rule.aspx?rule=45-04

Wylie, Sara and L. Albright. 2014. "WellWatch: reflections on designing digital media for multisited para-ethnography." Journal of Political Ecology 21:320-348.

Wylie, Sara A., K. Jalbert, S. Dosemagen, , and M. Ratto. 2014. "Institutions for Civic Technoscience: How Critical Making is Transforming Environmental Research" The Information Society 30(2):116-126. 